\title{
Uberização, ode à crise e precarização: desempenho, cansaço e colonização do tempo
}

\author{
Recebido em: 28/03/2021, aprovado em 21/05/2021 \\ 10.30612/mvt.v8i14.15017 \\ Agnes Cruz de Souza'
}

\begin{abstract}
RESUMO: O artigo discute perspectivas contemporâneas relacionadas ao mundo do trabalho e a intensidade das transformaçóes práticas, teóricas e discursivas no contexto da ordem capitalista neoliberal que invocam, por um lado, a noção de liberdade, autonomia, flexibilização e incentivo ao empreendedorismo e, por outro, redimensionam o âmbito da precarização configurando uma ordem facetada por reformas trabalhistas e sociais que reduzem o espaço de direitos. Referencia-se o processo de uberização do trabalho, a noção de cansaço, colonização de tempo 24/7 e a incrustação da precarização de categorias amplas e significativas de trabalhadores. Procura-se observar de que maneira os fatores elencados associam-se à legitimação, cristalização, incentivo e acentuação da falta de limites com relação à exploração e desestabilização das condiçóes de trabalho na atualidade. Conclui-se que a tecnologia inaugura novos padróes e processos de trabalho e estes são permeados por empregos precários, mal remunerados e instáveis afetando de forma ampla a vida dos trabalhadores uberizados, para além da esfera laboral. Os recursos metodológicos do texto perpassam por recortes teóricos das obras de Antunes (2020, 2018, 2009), Abílio (2020, 2019a, 2019b), Crary (2016) e Han (2017), além de aportes midiáticos e artísticos para referenciar a realidade das condiçôes e experiências do trabalho na atualidade: a série Years and years (2019) produzida pela BBC e HBO, o curta-documentário Vidas Entregues (2019) de Renato Prata Bitar, o filme Você não estava aqui (2019) dirigido por Ken Loach e o quadro modernista de Goya, O sono da razão produz monstros.
\end{abstract}

Palavras-chave: Uberização. 24/7. Sociedade do cansaço. Precarização.

\section{UBERIZATION, ODE TO CRISIS AND PRECARIOUSNESS: PERFORMANCE, FATIGUE AND THE COLONIZATION OF TIME}

ABSTRACT: The article discusses contemporary perspectives related to the world of work and the intensity of practical, theoretical and discursive transformations in the context of the neoliberal capitalist order that invoke, on the one hand, the notion of freedom, autonomy, flexibility and encouragement of entrepreneurship and, on the other, resize the scope of precariousness configuring an order faceted by labor and social reforms that reduce the space of rights. Reference is made to the

1 Doutora em Ciências Sociais pela Universidade Estadual Paulista (UNESP). Docente do Instituto Federal de Educação, Ciência e Tecnologia de São Paulo (IFSP) no Campus Boituva, agnesouzasoc@gmail.com 
process of uberization of work, the notion of tiredness, colonization of time 24/7 and the incrustation of the precariousness of broad and significant categories of workers. It seeks to observe how the listed factors are associated with legitimization, crystallization, encouragement and accentuation of the lack of limits in relation to the exploitation and destabilization of working conditions today. It is concluded that technology inaugurates new patterns and work processes and these are permeated by precarious, poorly paid and unstable jobs, affecting in a broad way the lives of uberized workers, beyond the labor sphere. The methodological resources of the text permeate theoretical excerpts from the works of Antunes (2020, 2018, 2009), Abílio (2020, 2019a, 2019b), Crary (2016) and Han (2017), as well as media and artistic contributions to reference reality of the conditions and experiences of work today: the series Years and years (2019) produced by the BBC and HBO, the short documentary Lives Delivered (2019) by Renato Prata Bitar, the film You were not here (2019) directed by Ken Loach and Goya's modernist painting, The Sleep of Reason Produces Monsters.

Keywords: Uberization. 24/7. Society of tiredness. Precariousness.

\section{UBERIZACIÓN, ODA A LA CRISIS Y LA PRECARIEDAD: RENDIMIENTO, FATIGA Y COLONIZACIÓN DEL TEMPO}

RESUMEN: El artículo analiza las perspectivas contemporáneas relacionadas con el mundo del trabajo y la intensidad de las transformaciones prácticas, teóricas y discursivas en el contexto del orden capitalista neoliberal que invocan, por un lado, la noción de libertad, autonomía, flexibilidad y fomento del emprendimiento y, por otro, redimensionan el ámbito de la precariedad, configurando un orden facetado por reformas laborales y sociales que reducen el espacio de derechos. Se hace referencia al proceso de uberización del trabajo, la noción de cansancio, la colonización del tiempo 24/7 y la incrustación de la precariedad de amplias y significativas categorías de trabajadores. Se busca observar cómo los factores enumerados se asocian con la legitimación, cristalización, estímulo y acentuación de la falta de límites en relación a la explotación y desestabilización de las condiciones laborales en la actualidad. Se concluye que la tecnología inaugura nuevos patrones y procesos de trabajo y estos están permeados por trabajos precarios, mal remunerados e inestables, que afectan ampliamente la vida de los trabajadores uberizados, más allá del ámbito laboral. Los recursos metodológicos del texto impregnan extractos teóricos de las obras de Antunes (2020, 2018, 2009), Abílio (2020, 2019a, 2019b), Crary (2016) y Han (2017), así como aportaciones mediáticas y artísticas de referencia a realidad de las condiciones y experiencias del trabajo hoy: la serie Years and years (2019) producida por la BBC y HBO, el cortometraje documental Vidas entregadas (2019) de Renato Prata Bitar, la película No estabas aqui (2019) dirigida por Ken Loach y la pintura modernista de Goya, El sueño de la razón produce monstruos.

Palabras Clave: Uberización. 24/7. Sociedad del cansancio. Precariedad. 


\section{INTRODUÇÃo}

Inerentes às transformaçóes do jogo capitalista global e do neoliberalismo, o mundo do trabalho em suas diversas vertentes e configuraçóes históricas não escapa aos ventos da flexibilização enquanto novidade que incorpora a noção de liberdade associada ao empreendedorismo. Vivenciamos, particularmente nas últimas décadas, profundas mudanças na forma e sentido do trabalho relacionadas como consumismo, o aprofundamento da crise do capital, a intensificação da presença da inteligência artificial e a reestruturação produtiva da acumulação flexível (ANTUNES, 2009).

A dimensão do trabalho é ressignificada e reorganizada por plataformas digitais que instituem a chamada uberização: rótulo para trabalhadores empreendedores que são remunerados por tarefa, demandas ou horas, que inaugura a falsa ideia do empregador de si mesmo sem qualquer tipo de garantia de jornada ou rendimentos, o que incide em implicaçóes importantes na dinâmica da gestão e nova organização da força de trabalho, uma vez que não há compromisso explícito de continuidade e oscilação de renda salarial. Os ganhos são irregulares, culminando em relaçóes de trabalho individualizadas e, ao mesmo tempo, invisibilizadas pelo discurso da prestação de serviços (ANTUNES; FILGUEIRAS, 2020).

Assim, paradigmas ditados pelo processo de globalização capitalista têm impactado a vida humana no século XXI exigindo cada vez mais que os indivíduos apresentem desempenho satisfatório no trabalho e, em função dessas exigências, estados patológicos marcados por adoecimentos neuronais dão espaço à comorbidades como a depressão, pelo déficit de atenção e/ou hiperatividade (TDAH), transtornos de bipolaridade e fadiga mental, consolidando violências sistêmicas dimensionadas pela esfera laboral. Estes fatores associam-se tanto ao desaparecimento, quanto a relativização do descanso, à constante necessidade de hiperatenção e do estar constantemente disponível gerando crescente sobrecarga, degradação psíquica e emocional mascarando um "bem viver que se tornou sobreviver" na sociedade que absolutiza o trabalho, reduzindo sujeitos à hiperatividade e histeria (HAN, 2017).

Ainda, a noção de tempo transforma-se radicalmente na era da globalização e os mercados adaptam a condição humana às suas nuances "[...] atuando em regime 24/7 - 24 horas por 7 dias na semana - e infraestrutura global para o trabalho e consumo contínuos [...] e agora é o homem que está sendo cobaia para o perfeito funcionamento da engrenagem” (CRARY, 2016, p. 13). Com isso, a configuração da identidade pessoal e social reorganizam-se para serem ajustadas à operação ininterrupta de mercados, redes de informaçóes e outros sistemas predominando:

Um ambiente 24/7 aparenta ser um mundo social, mas na verdade é um modelo não social, com desempenho de máquina - e uma suspensão da vida que não revela o custo humano exigido para sustentar sua eficácia [...]. A novidade está na renúncia absoluta à pretensão de que o tempo possa estar acoplado a quaisquer tarefas de longo prazo [...] um mundo sem sombras, iluminado 24/7, é a miragem capitalista final da pós-história (CRARY, 2016, p. 18-19).

Reformas trabalhistas (como a aprovada no governo de Michel Temer), a ampliação dos processos de terceirização total e quarteirizaçôes (BRASIL, 2017b) dialogam com a crise do desemprego e o crescimento da informalidade dimensionando trabalhos cada vez mais mal pagos e sem segurança previdenciária. Nesta esteira, as plataformas digitais orientam e conduzem um modelo social guiado por consumidores poupadores, levando a uma miríade proliferadora de empregos precários e à deterioração de direitos historicamente conquistados.

Além disso, as modalidades de trabalho são impactadas não só pela ameaça de desemprego, 
mas pelo aparecimento e desaparecimento de ocupaçóes, podendo gerar nova classe de "inúteis" com regime de exploração que tendem à irrelevância social.

Pensando nas dimensóes aqui elencadas, o presente artigo lança luz sobre aspectos do processo de uberização do trabalho com efeitos e potencializaçóes diante do que podemos verificar serem impactos contundentes na vida cotidiana dos trabalhadores sob sua égide: a relação obscurecida entre desenvolvimento tecnológico e precarização do trabalho.

Sugere-se nesse ínterim, que a precarização não traga em si a novidade para o mundo do labor contemporâneo, mas sim o uso das tecnologias (ABÍLIO, 2019a; 2019b). Deste modo, a tarefa preliminar consistirá na observação e análise dos meandros que ela perfaz: as mudanças na noção de tempo e sono, bem como seu respectivo processo de colonização retroalimentados pelo regime 24/7 (CRARY, 2016), o limiar da sociedade do cansaço e desempenho (HAN, 2017) e a perspectiva da irrelevância social como parte do redimensionamento das relaçôes de trabalho.

Na primeira parte do texto, o artigo perfaz os caminhos do debate que cerceia a uberização do trabalho enquanto perspectiva empreendedora relacionada à flexibilidade e liberdade. Posteriormente, busca-se refletir sobre a domesticaçáo contemporânea do tempo e sono como premissas de sucesso e alcance de êxito e por fim, aborda-se o modelo de sociedade de desempenho que se emoldura pelo cansaço elevado à potencialidade máxima de sujeição dos indivíduos rumo à precarização.

\section{UBERIZAÇÃO E O NOVO/VELHO “EMPREENDER”}

No curta-metragem documentário Vidas Entregues (2019), a realidade de trabalhadores da economia de compartilhamento na cidade do Rio de Janeiro é retratada a partir da vida prática nas ruas em atendimento às demandas dos aplicativos de entregas. A promessa de empreendedorismo apregoada como solução neoliberal para o desemprego estrutural demonstra que estamos a reproduzir mazelas antigas com novas roupagens.

Consolidando e estabelecendo globalmente novas formas de organizar, gerenciar e controlar as relaçôes no mundo do trabalho, a uberização faz parte de um tipo de economia de compartilhamento atrelada a "[...] novos negócios que usam a internet para conectar consumidores com provedores de serviços para trocas no mundo físico [...]" (SLEE, 2017, p. 33). Em suas origens, a economia de compartilhamento (termo recente e criado em meados de 2011) associava-se a um tipo de movimento social que combinava, afetivamente, comércio e causa no mundo digital, prometendo assim, auxiliar prioritariamente indivíduos vulneráveis rumo a tomarem o controle de suas vidas ao tornarem-se empresários de si ou microempresários (SLEE, 2017).

O modelo constitui-se pela apropriação corporativa da energia coletiva com apelo idealista, alegação de sustentabilidade, comunidade e anticonsumismo, representativo de um futuro - ou a promessa de democratizaçáo, a partir do uso da tecnologia para o bem e que carrega como traço comum a insistência de que "[...] o empreendedorismo (mais do que por exemplo, os serviços) é o caminho certo para resolver os problemas sociais. Acreditam que o lucro e o bem comum podem não apenas coexistir, mas também se beneficiar um do outro" (SLEE, 2017, p. 258). No entanto, o que se origina da ideia "o que é meu é seu" (compartilhar) na prática, se consolida com "o que é seu é meu” (expansão dos valores de mercado sobre as vidas de trabalhadores individuais). Ou seja, o fenômeno da uberização/economia de compartilhamento tem caráter fluido, volúvel e, estando em andamento em diferentes lugares do mundo, demonstra que contradiz sua ideia inicial de compartilhar e facilitar.

A intensificação da uberização do trabalho dialoga com uma realidade onde o sistema econômico pende a favor do setor financeiro e da plutocracia. Ignora-se o crescimento de empregos 
precarizados, além do desemprego e subemprego que se expandem em larga escala e de forma permanente. Carrega ainda a complexa materialidade de trilhar entre as chamadas ocupaçóes formais e informais um caráter instável e de ausência de identidade profissional, o que Abílio (2017) nomeia de trabalhadores amadores, demonstrando que paradoxalmente:

Por outro lado, as empresas uberizadas logram a conquista de coraçóes e mentes amargurados da classe trabalhadora, os partners - desempregados ou empregados precarizados em busca de um complemento para a sua renda ou de um ambiente menos despótico. As empresas da economia do compartilhamento navegam nas oportunidades que a sociedade do trabalho, em crise, oferece: consumidores em busca de baixo preço e trabalhadores em situação de desespero (OLIVEIRA; MORAES; SILVA, 2017, online).

A noção de empreendedorismo engendrada pela uberização é salutar: enquanto forma oculta de trabalho assalariado, notadamente o trabalho autônomo ou nanoempreendedor (ABÍLIO, 2019b) mistifica a ideia de proprietário/a de si mesmo, enquanto efetiva a conversão em proletário/a de si-próprio ou mesmo o autogerenciamento subordinado (ABÍLIO, 2019a) conformando, de acordo com Antunes (2018), o tripé terceirização, informalidade e flexibilidade:

[...] este novo fetiche do mundo tecnológico do capital permite, ao mesmo tempo, que se expanda o ideário fetichizado de que tudo está sob impulsão de uma neutra tecnologia, autônoma, quando é a engenharia informacional do capital que tem de fato o comando do algoritmo e, portanto, dos ritmos, tempos, produtividade e eficiência no universo microcósmico do trabalho individual, tendência que não para de se acentuar com a proposta da chamada Indústria 4.0, como se esta fosse um imperativo inexorável da tecnologia.

A ideia de liberdade e flexibilidade (trabalhar quando e onde quiser) propagada pelas empresas constitui, na verdade, a transferência deliberada de riscos para aumentar o controle sobre os/as trabalhadores/as, pois essa liberdade significa ausência de salário garantido e incremento de custos fixos que se convertem em responsabilidade dos mesmos (ANTUNES; FILGUEIRAS, 2020, p. 33).

$\mathrm{Na}$ realidade brasileira, a Reforma trabalhista aprovada em 2017 (Lei $\mathrm{n}^{\circ} 13.467$ ), sob a presidência de Michel Temer (MDB), expandiu o chamado home-office e tornou legais os contratos intermitentes, estes aprovados sem ampliação de debates, garantia de qualquer tipo de segurança ao trabalhador e sem regras claras para as contrataçôes. Especialistas dáo conta de observar que, da forma como foram homologadas as mudanças, praticou-se uma espécie de "vale tudo" para que se consolidassem as relaçóes de trabalho contemporâneas.

O modelo intermitente de trabalho no Brasil tem influência dos chamados "contratos zero-hora”, praticados na Inglaterra desde 2013. Assim, aquilo que no neoliberalismo apregoa a seduçáo da liberdade e flexibilidade, na prática dá consistência à flexibilização total do tempo e do salário de trabalhadores. $\mathrm{O}$ empregador não é obrigado a oferecer trabalho e em tese o trabalhador não precisa aceitá-lo. A uberização, dessa forma, alinha-se a este cenário e é promovida e legalizada sob o viés da subordinação e pauperização que não garantem o mínimo existencial para a sobrevivência, mascarada pela relação colaborador versus empresa. Além disso, conforme destaca Abílio (2019b, p. 2): 
[...] empresas apresentam-se não como contratantes, mas como mediadoras da oferta e procura; entretanto, são elas que detêm os meios de controle total sobre a distribuição do trabalho, do gerenciamento e estímulo da produtividade, de acesso às/desligamento das plataformas, além de obviamente, definirem o valor do trabalho de seus "parceiros".

Ainda, cumpre destacar que a uberização, da forma como se estabeleceu mundo afora, intensificou o processo de terceirizaçóes já amplamente praticados. No caso brasileiro, em 2017, a Lei de Terceirização ( $n^{\circ}$. 13.429) foi modificada, também no governo Michel Temer (BRASIL, 2017a), passando a atingir não só as chamadas atividades-meio, mas as atividades-fim das empresas. Ampliou-se, assim, mais um passo rumo às subcontrataçôes e às quarteirizaçóes com consequências graves que não só se relacionam à vinculação empregatícia,

[...] mas na transferência, para o trabalhador dos riscos, custos e parte do gerenciamento (subordinado), operando em novas lógicas, possibilitando novas formas de monopolização, apropriando-se das novas tecnologias para estabelecer novas formas de mapeamento, organização e controle do trabalho (ABÍLIO, 2019b, p. 4).

O modelo que se alastra nas relaçóes de trabalho contemporâneas associa-se à reestruturação do sistema de acumulação flexível capitalista, permitindo efêmera e transitória superação de sua crise com o respaldo da tecnologia. No entanto, quando resgatamos historicamente as conquistas dos trabalhadores, a uberização remonta ao regresso de práticas e condiçôes de labor muito semelhantes às perpetradas antes que a classe pudesse de fato garantir direitos, retirados náo só da carteira de trabalho, mas das responsabilidades de neopatróes, que apesar da invisibilidade "empreendedora" coexistem e mantém seu modus operandi (ABÍLIO, 2017; 2019, 2019b; ANTUNES, 2009; 2018; OLIVEIRA; MORAES; SILVA, 2017).

Como relatam alguns dos entrevistados do curta documentário: "Empreendedor eu não me vejo não. Eu náo tenho patrão, porque eles não dão suporte nenhum pra gente" [...] "Desesperada! (Risos) Mas microempreendedora eu não sou não [...] eu sou uma pessoa desesperada porque eu não tenho emprego" (VIDAS ENTREGUES, 2019). Dessa forma, a tecnologia que permeia o modelo e adaptações do trabalho uberizado intensifica sobremaneira a precarização da vida e condições dos trabalhadores, questão que será ampliada na seção seguinte.

\section{24/7, AS NOVAS DINÂMICAS INTERNACIONAIS DO CAPITALISMO E EXPLORAÇÃO DA ERA DIGITAL: \\ A DOMESTICAÇÃO E COLONIZAÇÃO DO TEMPO E SONO}

Numa das pinturas mais significativas do modernismo, $O$ sono da razáo produz monstros, o espanhol Francisco de Goya criticava a ignorância e a profusão de ideias perigosas e falsas. $\mathrm{O}$ artista produziu suas obras na passagem dos séculos XVIII para o XIX e hoje, em pleno século XXI, a luz e a verdade que tanto importavam para sua obra criativa se traduzem ainda em sono obscuro que convence os indivíduos de que pela ode à racionalidade, o tempo é o nosso maior bem, e, portanto, não pode ser desperdiçado para que se atendam aos ditames mercadológico-consumistas da era global.

Antes que o termo 24/7 ou a colonização do tempo se tornassem objetos de investigação e 
mesmo conhecidos no linguajar cotidiano recente, a ideia de cansaço, exaustão e exploração sempre se fez presente na vida humana. Diferentes períodos históricos apropriaram-se, por meio do trabalho, de limites da fadiga aos quais o corpo humano poderia chegar. No entanto, ao nos referirmos à atualidade, a novidade está em como tecnologia em suas novas modalidade de exploraçáo e a internacionalização das dinâmicas do capitalismo entrelaçam de forma intensa o fenômeno:

Muitas dessas transformaçóes se consolidaram ou se radicalizaram com a popularização e a conexâo constante de dispositivos comunicacionais digitais e a internet, assunto que vem sendo tratado de forma exaustiva pela sociologia. Como efeitos, temos ao mesmo tempo o lento fim dos empregos e o esvaecimento das fronteiras entre o trabalho e o não trabalho. Além disso, os dispositivos tecnológicos e a rede vêm propiciando o surgimento de novos modelos de trabalho e de exploração de serviços (FIRMINO; CARDOSO, 2018).

Para o perfeito funcionamento dessa engrenagem que não para, o ser humano é o protagonista juntamente com seu tempo, liberdade e sono - precarizados em nome da velocidade e infraestrutura global para o trabalho e consumo contínuos. Liberdade plena e tempo tornaram-se mercadorias supremas, pois o descanso e regeneração dos seres humanos são custosos ao capitalismo contemporâneo (CRARY, 2016).

A uberização do trabalho não escapa à lógica do $24 / 7$ sendo, desse modo, por ela retroalimentada como um tempo sem tempo, sem demarcação material, sem sequência ou recorrência. A alucinação da presença, operaçôes incessantes e automáticas, além da permanência inalterável, compóem suas substâncias na atualidade e a vida comum é operacionalizada em nome da técnica, do algoritmo e dos smartphones. É uma temporalidade impossível que solapa qualquer intervalo ou variaçáo, uma vez que:

Com uma oferta infinita e perpetuamente disponível de solicitações e atraçóes, o 24/7 incapacita a visão, por meio de processos de homogeneização, redundância e aceleração. Apesar de afirmaçóes em contrário, assistimos à diminuição das capacidades mentais perceptivas em vez de sua expansão e modulação (CRARY, 2016, p. 43).

O consumo e a prestação de serviços integram-se harmonicamente à colonização do tempo inserida no modelo 24/7, uma vez que a redução temporal da tomada de decisôes, a eliminação do tempo inútil de reflexão e a contemplação dão margem ao tempo sem tempo, isto é, "o encarceramento e o controle implacáveis do tempo e da experiência” (CRARY, 2016, p. 49).

Em seu recente filme, Você não estava aqui (2019), o diretor Ken Loach retrata a realidade do trabalho uberizado na perspectiva inglesa. O protagonista, empreendedor de si mesmo, deve, a todo custo, ajustar suas demandas à precisão de horários de entrega e atendimentos diários cronometrados, inspecionados e estabelecidos pela franquia de logística. Retrata-se uma faceta e inovação do capitalismo contemporâneo que consiste na simulação contínua do novo (tecnologia), enquanto que na prática relaçóes de poder, trabalho e controle sobre os trabalhadores permanecem os mesmos. Crary (2016) ressalta que em:

[...] boa parte do século XX, a produção de novidades, apesar de seu caráter repetitivo e nulo, era frequentemente vendida de maneira a satisfazer a imaginação social de um futuro mais avançado ou pelo menos diferente. No quadro do 
futurismo de meados do século XX, os produtos comprados e incorporados à vida pareciam vagamente relacionados a evocaçóes populares de prosperidade global futura, da substituiçáo benfazeja do trabalho humano pela automação, da exploração espacial, da erradicação do crime e de doenças e assim por diante [...]. O 24/7 é estruturado em torno de objetivos individuais de competitividade, promoção, aquisição, segurança pessoal e conforto à custa dos outros. O futuro está tão à máo que só pode ser imaginado como idêntico à luta pelo ganho ou pela sobrevivência individual no mais superficial dos presentes (CRARY, 2016, p. 49-50).

A economia compartilhada e o futuro preconizado, no entanto, estáo mais que presentes e não foram capazes de romper com as amarras do passado de exploração, precarização e exaustão extrema de trabalhadores, hoje uberizados. A reconfiguração de sistemas, modelos e plataformas tiveram um papel decisivo na reinvenção do sujeito e na intensificação de seu controle. Conforme salientam Antunes e Filgueiras (2020):

É por isso que, nos dias atuais, é difícil encontrar qualquer modalidade de trabalho que não tenha alguma forma de interação e dependência de celulares, computadores, smartphones e assemelhados, sendo que a gestão praticada nos moldes das plataformas tornou-se potencialmente expansível para um imenso conjunto de ramos e setores. São estabelecidas relações sem qualquer limite de jornada, renda, saúde, segurança. Nesse sentido, é necessário acentuar que esse vilipêndio em relação ao trabalho não é uma possível remissão ao futuro. No presente, a expansão do trabalho digital vem demolindo a separação entre o tempo de vida no trabalho e o tempo de vida fora dele (ANTUNES; FILGUEIRAS, 2020, p. 38).

No entanto, parte da cultura que se moldou na contemporaneidade e foi amplamente incorporada ao mundo do trabalho, trouxe a ideia de que poderia haver uma gratificaçáo individual a partir da imitação de ritmos, eficiência e dinamismo impessoais de mecanização. A permeabilidade e indistinção entre tempo de trabalho e de lazer, "[...] habilidades e gestos que seriam restritos ao local de trabalho agora integram universalmente a tessitura 24/7 de nossa vida eletrônica" (CRARY, 2016, p. 67) expropriando-nos do tempo, da prática e mesmo da liberdade.

A reificação humana no modelo uberizado de trabalho recriou um indivíduo numa concepçáo de si que potencializasse e, ao mesmo tempo, viabilizasse sua presença e participação em ambientes com velocidades digitais. Ou seja, típicas miragens eletrônicas que constituem o mercado conectado do consumo global e sujeitos inventados para serem compatíveis entre o que o humano é capaz e um reino de escolhas não verossímeis para suas capacidades. Anula-se o tempo, o sono e a própria vida humana em torno do ideário de autogerenciamento subordinado (ABÍLIO, 2019a) e legitimado pelo discurso da liberdade. O protagonista de Você náo estava aqui ilustra de forma contundente a nova realidade, desejo de mudanças e perspectivas quando entrevistado para fazer parte de uma franquia de motoristas:

Então, prefiro trabalhar sozinho agora, ser meu próprio chefe.

Já recebeu o seguro-desemprego? 
Não. Eu tenho orgulho. Prefiro morrer de fome.

Gostei do que ouvi Ricky. Henry tinha razão, você é guerreiro. Vamos só esclarecer algumas coisas pra começar. Aqui você não é contratado, você embarca. Gostamos de dizer "embarcar". Não trabalha para nós, trabalha conosco. Não dirige para nós, presta serviços. Não temos contratos de emprego. Não há metas a cumprir. Você recebe o Padrão de Entrega. Não há salários, há honorários. Ficou claro?

Sim. Está tudo bem.

Você não bate ponto, você fica à disposição. Se assinar conosco, será um motorista franqueado. Senhor do seu destino, Ricky. Isso separa os perdedores dos guerreiros. Você topa?

Sim. Eu espero uma oportunidade como esta há séculos (VOCÊ NÃO ESTAVA AQUI, 2019, online).

A oportunidade uberizada da vez transforma trabalhadores em indivíduos autossuficientes, donos de seu próprio tempo e destino, disponíveis, determinados, colaboradores e cumpridores de metas, conforme o padrão do que entregam ao final do dia enquanto franqueados batalhadores.

Firmino e Cardoso (2018) incrementam faceta curiosa (que pelo espaço e limitaçôes destinadas ao artigo não serão ampliadas) que identifica engenhosa perspectiva com possibilidade de maximização e exploração da força de trabalho, nomeada pelos autores de "uberização da Uber". Num informal e antropológico papo de corrida realizada por eles ao utilizarem o aplicativo, detalhes de um esquema ardiloso de manobra das relaçóes de trabalho foram observados:

Daniele era motorista profissional, contratada por Michel para servir sua família. Seu trabalho seguia todas as regras trabalhistas, como jornada de oito horas diárias e registro em carteira. Entretanto, nas horas em que estava a trabalho e sem atividades específicas com a família de Michel, Daniele era obrigada a realizar corridas como motorista Uber, com as seguintes condiçóes: todo valor repassado pela Uber iria diretamente para a conta do chefe; o e-mail cadastrado no serviço era o de Michel, que monitorava valores e trajetos conforme estes aconteciam; em caso de acidentes, a responsabilidade recairia sobre Daniele; celular e veículo eram de propriedade de Michel; e não havia a possibilidade de trabalhar sem aceitar essas condiçóes (FIRMINO; CARDOSO, 2018).

A dupla exploração ajustada ao contexto prestação de serviços para a Uber descrita pela motorista, revela a complexidade, ambiguidade e organicidade pouco éticas numa articulação perversa em contexto onde salta aos olhos a precarização da própria liberdade. Segundo os autores, foi curioso e ao mesmo tempo surpreendente verificar que "numa atividade táo característica da sharing economy e do self empreendedor, os velhos conceitos de mais-valia e de propriedade dos 'meios de produção’ pudessem fazer tanto sentido" (FIRMINO; CARDOSO, 2018).

O impacto profundo no sentido de valorização do indivíduo no processo e relações de trabalho permeadas pela uberização tem como consequência o ataque à coletividade e seus valores, uma vez que "por meio da noção de que liberdade é estar livre de qualquer dependência em relação aos 
outros" (CRARY, 2016, p. 124) vive-se a subjugação completa à lógica do ser "livre" neoliberal e com isso, o 24/7 oferta a ilusão de um tempo sem espera, de atendimentos instantâneos e do gerenciamento eletrônico de nossas vidas e cotidiano, impedindo o cuidado com os outros e de si mesmo. Amplia-se assim mais um espectro da precarização programada e sistematizada do "empreender" na realidade global e flexibilizada.

\section{CANSAÇO, DESEMPENHO E NOVAS COERÇÕES: INDIVÍDUO NO TOPO DA CADEIA PRODUTIVA}

$\mathrm{O}$ trabalho enquanto histeria e hiperatividade são características atreladas à contemporaneidade; regido pela ode ao desempenho e marcado por adoecimentos neuronais típicos do século XXI (depressão, fadiga, TDAH, transtorno de bipolaridade e Síndrome de Burnout). Neste contexto, vivenciam-se processos de violência ditados pelo exagero da positividade num modelo social que abarca a superprodução, a supercomunicação e o superdesempenho dos indivíduos (HAN, 2017).

No contexto da uberização, a concepção de liberdade cede espaço para a constituição de novas formas coercitivas do sujeito pós-moderno, em um modelo social que exagera e enaltece a individualidade, além de propagar um viver ativamente para gerar cansaço e esgotamento excessivos. Nesta sociedade do desempenho, o inconsciente social maximiza produçáo e produtividade, dando poder ilimitado a projetos, iniciativas e motivação aos trabalhadores autogeridos. Configura-se dessa forma, uma exploração com sentido de liberdade, ou seja, o "explorador é ao mesmo tempo explorado. Agressor e vítima não podem ser mais distinguidos. Os adoecimentos psíquicos da sociedade de desempenho são precisamente as manifestaçôes patológicas dessa liberdade paradoxal" (HAN, 2017, p. 30).

$\mathrm{O}$ tédio profundo que marca a sociedade atual tem sua raiz no excesso de positividade. De acordo com Han (2017), a crescente cobrança pela sobrecarga de trabalho e exigência para que indivíduos sejam multitarefas gera um excesso de estímulos, informaçóes e impulsos que levam ao retrocesso em termos do bem viver, que literalmente se transforma na sobrevivência possível. O descanso desaparece, a colonização do tempo transforma-se num imperativo e a absolutização do trabalho incentiva plenamente que sujeitos sejam ativos. Estes fatores aparecem enquanto positividade em uma:

Sociedade do trabalho, na qual o próprio senhor se transformou num escravo do trabalho. Nessa sociedade coercitiva, cada um carrega consigo seu campo de trabalho. A especificidade desse campo de trabalho é que somos ao mesmo tempo prisioneiros e vigia, vítima e agressor. Assim, acabamos explorando a nós mesmos (HAN, 2017, p. 47).

Dentre as muitas associaçóes entre o uso de drogas psicotrópicas e instrumentos de comunicação, uma delas está na produção de formas de conformidade social. O uso difundido de remédios para transtornos de déficit de atenção e hiperatividade (TDAH) é frequentemente motivado pela esperança de melhorar o desempenho e competitividade no trabalho e, mais grave, o vício em metanfetamina está muitas vezes ligado às ilusôes destrutivas de desempenho e autoengrandecimento (CRARY, 2016).

A sociedade do cansaço apresenta como perspectiva de melhora cognitiva dos indivíduos o “doping cerebral”, isto é, associados a uma máquina de desempenho, é possível empreender livre de perturbaçóes e maximizando a execução de suas atividades uma vez que o "doping possibilita de certo modo um desempenho sem desempenho" (HAN, 2017, p. 69). Ativa-se o excesso de positividade 
social, para sujeitos plenamente ativos, no entanto, o processo gera cansaço, esgotamento excessivo além de isolar e individualizar trabalhadores, rompendo com a ideia de comunidade, proximidade e elementos comuns entre todos. Com isso:

A coaçáo do desempenho força-o a produzir cada vez mais. Assim, jamais alcança um ponto de repouso da gratificação. Vive constantemente num sentimento de carência e de culpa. E visto que, em última instância, está concorrendo consigo mesmo, procura superar a si até sucumbir. Sofre um colapso psíquico, que se chama de Burnout (esgotado). O sujeito de desempenho se realiza na morte. Realizar-se e autodestruir-se, aqui, coincidem (HAN, 2017, p. 85).

A flexibilidade e liberdades celebradas demarcam relaçóes capitalistas contemporâneas de trabalho pautadas pela ampliação da exploração, precarização, eficiência e produtividade produzindo seres fracassados, regidos pela violência autogerada e que se imaginam como livres nesse processo. Amplia-se a vida desnuda e fora da ordem do direito, gerando estados de exceção que produzem e normalizam o desprovimento de direitos historicamente conquistados em nome do empreender a si mesmo, afinal há trabalho em qualquer lugar e qualquer hora - laptops e smartphones formam o campo de trabalho móvel do neoliberalismo.

\section{CONSIDERAÇÕES FINAIS: \\ FUTURO E CRISE DO TRABALHO CONTEMPORÂNEO -OS SENTIDOS DO “EMPREENDER"}

A série Years and years, produzida pela HBO em 2019, retrata o impacto da tecnologia em nosso cotidiano e se propóe a discutir criticamente como, num futuro distópico próximo, serão vivenciadas mudanças desencadeadas em várias esferas da vida dos indivíduos: sociais, culturais, econômicas e psicológicas.

O diálogo em destaque abaixo é apresentado no episódio seis (o último) da temporada um. Uma família inglesa (a que protagoniza a série) impactada pela crise econômica, desemprego e com membros desempenhando trabalhos precarizados ouve atentamente a avó no jantar da família. Revelando misto de indagação num primeiro momento, muitos não compreendem o porquê do diálogo por ela colocado, no entanto lentamente a cena leva os protagonistas a refletirem sobre as mudanças e a culpa que carregavam pelo estado das coisas que ali a matriarca proferia:

Absolutamente tudo o que deu errado é culpa de vocês [...] Porque nós somos. Cada um de nós. Podemos ficar aqui o dia todo culpando os outros [...], mais ainda é culpa nossa. Vocês sabem por quê? Eu vi, começou a dar errado nos supermercados, quando substituíram as mulheres dos caixas pelos caixas automáticos [...] Isso não é nossa culpa? Sim, mas não fizeram nada. Há 20 anos quando apareceram vocês protestaram? Escreveram carta de reclamação? Compraram em outro lugar? Não! Vocês acharam ruim, mas se conformaram! E agora aquelas mulheres não existem mais. E nós deixamos isso acontecer. [...] Eu acho que gostamos desses caixas. Queremos isso. Porque podemos passar, pegar nossas compras sem ter que olhar nos olhos daquela mulher. A mulher que ganha menos que nós. Ela não existe mais, foi despedida. Muito bem, então, sim é culpa nossa. Este mundo fomos nós que construímos. Parabéns! Saúde! (YEARS AND YEARS, 2019, online).

O mundo globalizado e imerso na tecnologia, se referenciado em termos de processo histórico, vivencia crescimento exponencial do setor de serviços e, dessa forma, as mudanças do 
capitalismo internacionalizado e ajustes neoliberais fizeram surgir ocupaçóes instáveis, inseguras, com baixas remuneraçóes e desorganizadas em termos de reconhecimento dos trabalhadores enquanto classe (ANTUNES, 2018).

Para reflexão sobre tal cenário, destacou-se a uberização enquanto um processo que une o novo (economia de compartilhamento) ao velho, salientando-se que, como promessa coletiva, não efetiva o empreendedorismo, reforça a instabilidade de trabalhadores amadores (ABÍLIO, 2019b), além de consolidar o tripé terceirização, informalidade e flexibilidade (ANTUNES, 2018), protagonizando conjuntura de subcontrataçôes e quarteirizações na prestação de serviços.

Além disso, no mundo do trabalho contemporâneo, o modelo ocupa forma de organizaçáo, gerenciamento e controle do trabalho que conformam o trabalhador just in time, disponível e descartável (ABÍLIO, 2019a; 2019b) reiterando práticas envoltas na precarização e exploração que não foram superadas, mas ressignificadas, recompostas e adaptadas.

Do ponto de vista das novas dinâmicas internacionais do capitalismo global, demarca-se o controle total da vida de trabalhadores no sentido de domesticar, colonizar e controlar, via sistema $24 / 7$, seu tempo e sono em nome dos preceitos da temporalidade mercado x consumo.

Ainda, cansaço e desempenho, acoplam paradoxalmente o modelo multitarefas de superprodução, supercomunicação e superdesempenho (HAN, 2017) dos indivíduos, gerando fadiga e esgotamento excessivo na esfera laboral. O descanso desaparece dando espaço aos adoecimentos neuronais típicos do século XXI.

A uberização, seus impactos e transformaçôes repercutem para além da esfera do trabalho e denotam sinal de sua crise, embora, ao mesmo tempo, confundam-se enquanto novidade (apoiada no avanço da tecnologia) que impulsiona a liberdade e flexibilidade: promove o experienciar cotidiano sem a separação casa, trabalho, lazer, diversão e pausa. Assim, devidamente adaptados e conectados numa simbiose plena que concretiza o empreender ilusório, falso e precarizado, produz sujeitos relegados ao cansaço, negação/subjugação do sono e do tempo, aniquilando a própria capacidade de se enxergarem como algozes de si mesmos.

\section{REFERÊNCIAS}

ABÍLIO, Ludmila Costhek. Plataformas digitais e uberização: Globalização de um Sul administrado? Contracampo, Niterói, vol. 39, n. 1, p. 12-26, abr./jul. 2020.

Uberização: Do empreendedorismo para o autogerenciamento subordinado. Psicoperspectivas, Valparaíso, vol. 18, n. 3, p. 41-51, nov. 2019a.

. Uberização: A era do nanoempreendedor de si? Anais do 43o. Encontro da ANPOCS. Caxambu, Brasil: ANPOCS, 2019b.

Uberização do trabalho: A subsunção real da viração, Site Passapalavra/ Blog da Boitempo, 2017. Disponível em https://blogdaboitempo.com.br/2017/02/22/uberizacao-do-trabalho-subsuncao-real-da-viracao/ Acesso em: 13 fev. 2020.

ANTUNES, Ricardo. "Uberização" do trabalho: caminhamos para a servidão, e isso ainda será um privilégio. Entrevista. Revista IHU On-Line, agosto de 2019. Disponível em: http://www.ihu. unisinos.br/78-noticias/591102-uberizacao-nos-leva-para-a-servidao-diz-pesquisador Acesso em: 18 abr. 2020. 
. O privilégio da servidáo: o novo proletariado de serviços na era digital. São Paulo: Boitempo, 2018.

Os sentidos do trabalho: ensaio sobre a afirmação e a negação do trabalho. 2a ed. São Paulo/SP: Boitempo, 2009.

; FILGUEIRAS, Vitor. Plataformas digitais, Uberização do trabalho e regulação no Capitalismo contemporâneo. Contracampo, Niterói, vol. 39, n. 1, p. 27-43, abr./jul. 2020.

BRASIL. Lei no ${ }^{\circ} 13.429$ de 31 de Março de 2017. Dispóe sobre o trabalho temporário nas empresas urbanas e dá outras providências; e dispóe sobre as relações de trabalho na empresa de prestação de serviços a terceiros, 2017a. Disponível em: http://www.planalto.gov.br/ccivil_03/_ato20152018/2017/lei/113429.htm Acesso em: 10 abr. de 2020.

Lei no 13.467 de 13 de julho de 2017. Altera a Consolidação das Leis do Trabalho (CLT) a fim de adequar a legislação às novas relações de trabalho, 2017b. Disponível em: http://www. planalto.gov.br/ccivil_03/_ato2015-2018/2017/lei/113467.htm. Acesso em: 2 mar. 2020.

CRARY, Jonathan. 24/7 Capitalismo tardio e os fins do sono. Trad. Joaquim Toledo Jr. São Paulo: Ubu, 2016.

HAN, Byung-Chul. Sociedade do cansaço. 2a ed. Petrópolis/ RJ: Vozes, 2017.

FIRMINO, Rodrigo; CARDOSO, Bruno. Uberização da UBER. Le Monde Diplomatique, 2018. Disponível em: https://diplomatique.org.br/a-uberizacao-da-uber. Acesso em: 12 mai. 2018.

OLIVEIRA, Marco Antonio Gonsales de; MORAES, Rodrigo Bombonati de Souza e SILVA, Rogério de Souza. Luta de classes na era do UBER, Outras palavras, 2017 Disponível em: https:// outraspalavras.net/posts/luta-de-classes-na-era-do-uber/. Acesso em: 5 jan. 2018.

SLEE, Tom. Uberizaçáo. A nova onda do trabalho precarizado. Trad. João Peres. São Paulo: Elefante Editora, 2019.

VIDAS entregues. Direção de Renato Prata Biar, Documentário, 2019. Disponível em: https:// www.youtube.com/watch?v=cT5iAJZ853c\&feature=youtu.be. Acesso em: 7 jan. 2020 .

VOCÊ não estava aqui. Direção de Ken Loach, Filme, 2019. 101 minutos.

YEARS and years. Direção de Russell T. Davies, Série, BBC e HBO, 2019, Temporada 1. 